\title{
Circumanal Gland
}

National Cancer Institute

\section{Source}

National Cancer Institute. Circumanal Gland. NCI Thesaurus. Code C77610.

A large apocrine gland located in the area surrounding the anal orifice. 